\title{
Strengthening of Concrete Metallic Chips
}

\author{
Y. Bouafia, S. Djebali, D. Atlaoui, and M. S. Kachi
}

\begin{abstract}
This work is a part of industrial waste development program. It is devoted to the study of recyclability, as reinforcement for concrete, of chips resulting from the machining of steel parts. We're interested in this study to the rheological behavior of chips reinforced fresh concrete and its mechanical behavior at a young age. The evaluation of the workability with the LCL workabilimeter showed that optimal sand over gravel ratios are $S / G=0.8$. Mechanical characterization tests (direct tension, compressive and flexural) show that the mechanical properties of chips concrete are comparable to those of the two selected reference concretes (concrete reinforced with conventional fibers: Eurosteel fibers corrugated and Dramix fibers). Chips provide a significant increase in strength and some ductility in the post-failure behavior of the composite to concrete witness. Recycling chips as reinforcement for concrete can be favorably considered.
\end{abstract}

Index Terms - Concrete, fiber, recyclability, direct tension.

\section{INTRODUCTION}

This work is devoted to the study of the mechanical behavior, under different loads, of concrete reinforced with metallic chips resulting from the machining of steel parts. Tensile tests, simple compression and three-point bending are performed to determine the performance conferred by using chips. These are characterized by the tensile strength and pull out test. Optimal composition of the composite is also developed. Comparing the performance of this concrete with those of reinforced concrete with conventional fibers will provide information on the relevance of the use of wood chips as reinforcement for concrete.

\section{EXPERIMENTAL TECHNIQUES}

Two types of experiments are carried out in this study:

- The tests of optimizing the composition of reinforced concrete chips with the workability developed by the Central Laboratory of Roads and Bridges (L.C.P.C.) ${ }^{1}$.

- The mechanical characterization tests of reinforced concrete chips by direct tension, simple compression and three-point bending. The tensile tests and bending are directly carried out, at a speed of $0.05 \mathrm{~mm} / \mathrm{min}$ loading, on a tensile testing machine under the brand "IBERTEST 200". The loading pattern of the bending test is shown in Fig. 1. Compression tests are performed on a hydraulic press mark AUTOTEST, $2000 \mathrm{kN}$ capacity under a load speed of $0.5 \mathrm{MPa} / \mathrm{s}$.

Manuscript received March 16, 2013; revised July 11, 2013.

The authors are with the University "Mouloud Mammeri" of Tizi-Ouzou (e-mail: $\quad$ youcef.bouafia2012@yahoo.com, djebalisaid@yahoo.fr, atlaouidjamal2005@yahoo.fr,kachi_ms@yahoo.fr).

1 L.C.P.C. : Central Laboratory of Bridges and Roads, France "Laboratoire Centrale des Ponts et Chaussées, France".

\section{MATERIALS AND SPECIMEN GEOMETRY}

- The tensile specimens, from 28 days of age, are dumbbell-shaped cross-section of $90 \times 90 \mathrm{~mm}^{2}$ and length $100 \mathrm{~mm}$ (see Fig. 2).

- The test specimens are compression cylinder $160 \mathrm{~mm}$ in diameter and $320 \mathrm{~mm}$ in length and those of the bending parallelepipeds are $100 \times 100 \mathrm{~mm}^{2}$ in section, and $250 \mathrm{~mm}$ in length.

- The optimized composition of the concrete matrix is determined and given later (see Table I, § IV).

- Chips (see Fig. 2), of rectangular cross-section $1 \times 3 \mathrm{~mm}^{2}$, are spirally winding diameter of about $8 \mathrm{~mm}$ and length 50 mm. Six levels of chips $(\mathrm{W}=0.4 \%, \mathrm{~W}=0.6 \%, \mathrm{~W}=$ $0.8 \%, \mathrm{~W}=1 \%, \mathrm{~W}=1.2 \%$ and $1.5 \%$ with $\mathrm{W}=$ volume percentage content chips) are used for this study.

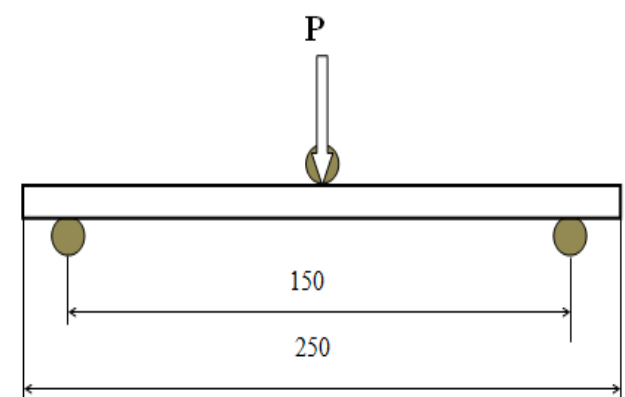

Fig. 1. Loading scheme (mm)
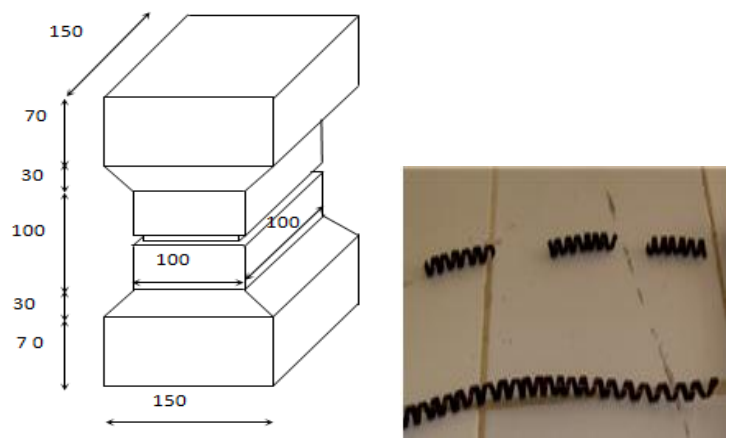

Fig. 2. Geometry of specimens (mm) and chips.

\section{RESULTS AND DISCUSSION}

\section{A. Optimization of the Composition of the Fiber Concrete}

We determined the approximate composition of the concrete matrix by the classical method and characterized pulls and resistance of chips. Characterization at pullout of chips was to determine the minimum length for which anchor the fiber pullout and not rupture. For this purpose, we considered five lengths $(10,20,30,40$ and $50 \mathrm{~mm})$ chips, each with 3 waves, 5 and 8 undulations. During this test (see Fig. 3), the fiber has broken for the five anchoring lengths. For the length of $10 \mathrm{~mm}$, cracking and spalling of concrete 
around the fiber were observed. This seems to be the limiting length, below which the fiber pulls rather than break. The test for characterizing the rupture strength of the chips has an average value of $195 \mathrm{MPa}$ (see Fig. 4). Strong dispersion due to the nature of the fibers was observed in this trial.

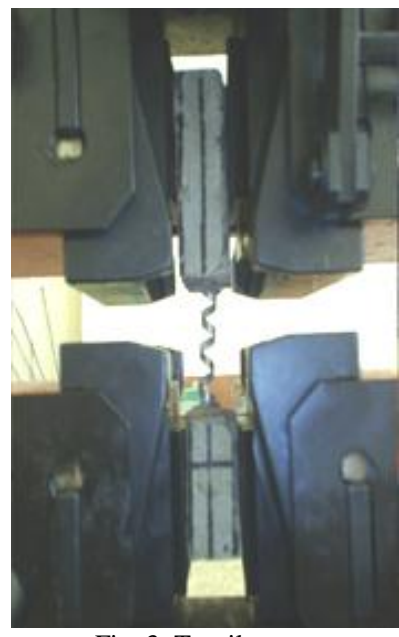

Fig. 3. Tensile test

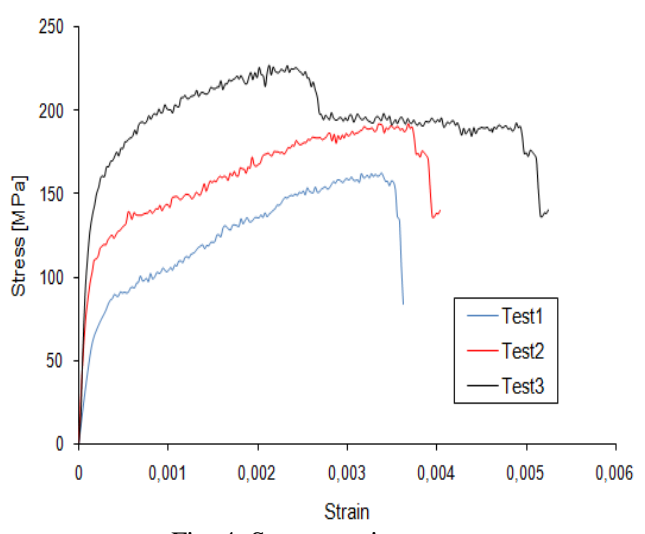

Fig. 4. Stress-strain curve.

The optimized composition obtained by the experimental method, developed by Baron-Lesage, in [1]-[4], and using the workabilimeter produced by the Central Laboratory of Roads and Bridges (LCPC), is given in Table I.

TABLE I: OPTIMISED COMPOSITION

\begin{tabular}{|l|c|}
\hline \multicolumn{1}{|c|}{ Concrete composition for 30 litres } & $\mathrm{S} / \mathrm{G}=0.8$ \\
\hline Sand $0 / 3(\mathrm{~S})[\mathrm{kg}]$ & 23.91 \\
Gravel $3 / 8(\mathrm{G})[\mathrm{kg}]$ & 3.19 \\
Gravel $8 / 15(\mathrm{G})[\mathrm{kg}]$ & 26.70 \\
Cement CPJ CEM II/A 42.5(C) $[\mathrm{kg}]$ & 11.40 \\
water (E) $[\mathrm{kg}]$ & 6.20 \\
Fluidifying agent $(0.05 \%$ of the cement weight $)[\mathrm{ml}]$ & 5.7 \\
\hline
\end{tabular}

The ratio of sand/gravel $\mathrm{S} / \mathrm{G}=0.8$ has minimum flow time between 10 and 15 seconds for the different content chips. These minima correspond to the optimum range recommended by the LCPC.

\section{B. Characterization by Direct Tensile Test}

For concrete control (see Fig. 5), the stress varies almost linearly with the deformation until the fracture strength $\sigma_{c p}$. As soon as this threshold is reached, it drops abruptly to vanish. For reinforced concrete with the chips, it increases linearly up to the beginning of stress cracking of the matrix $\sigma_{c}$ From this point, depending on the fiber content, this increase
From this point, depending on the fiber content, this increase slows and then resumes until it reaches the tensile strength of the matrix $\sigma_{c p}$. Once this value is reached, it drops suddenly and then stabilizes at a value corresponding to the residual stress $\sigma_{\text {rés }}$ to the complete failure of the specimen. Residual strength $\left(\sigma_{\text {res }}\right)$ increases with $\mathrm{W} \%$ up to $0.6 \%$ and then stabilizes before declining sharply to values greater than $1 \%$ (see Fig. 6). For $\mathrm{W}=0.4 \%$ resistance $\left(\sigma_{c p}\right)$ of the composite increases slightly. A similar trend is observed with the Young's modulus E. Stress and strain, $\sigma_{c}$ and $\varepsilon_{c}$, start cracking decreases with increasing $\mathrm{W} \%$. Deformations corresponding to rupture $\varepsilon_{\text {rup }}$ early level of ductility increase with $\mathrm{W} \%$, they recorded their maximum value for $\mathrm{W}=0.8 \%$. Beyond $\mathrm{W}=1 \%$ every tensile mechanical properties decrease. Concrete composition which guarantees a better tensile behavior is that chips containing $0.6 \%$ (see Fig. 6 and Table II).

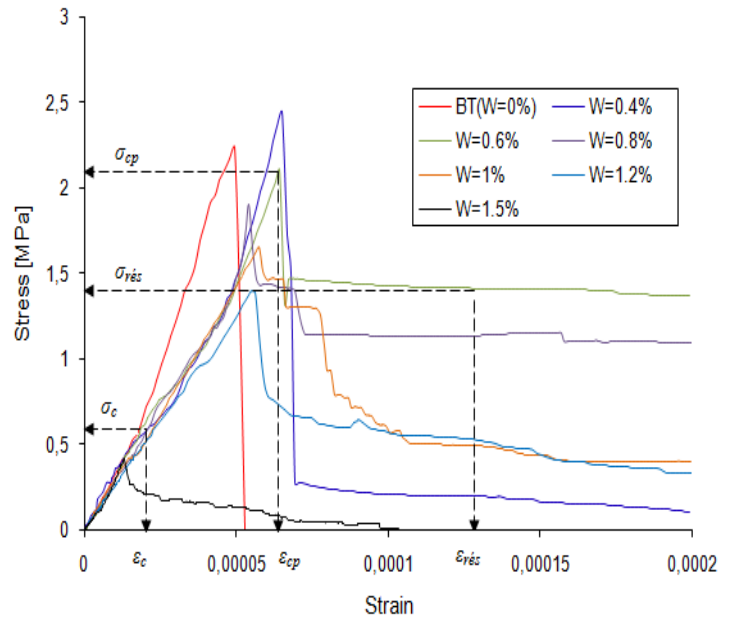

Fig. 5. Stress-strain curve.

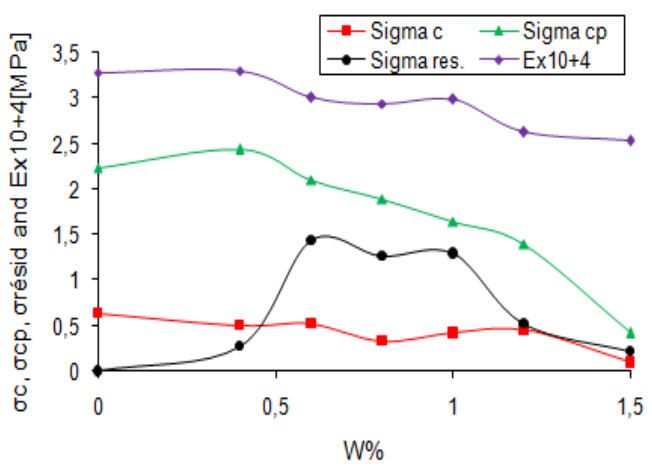

Fig. 6. Tensile mechanical characteristics, $\mathrm{W}=0,6 \%$.

TABLE II: TENSILE MECHANICAL CHARACTERISTICS MEASURED.

\begin{tabular}{|l|l|l|l|l|l|l|}
\hline$W \%$ & $\sigma_{c}[\mathrm{MPa}]$ & $\varepsilon_{c} \times 10^{-5}$ & $E[\mathrm{MPa}]$ & $\sigma_{c p}[\mathrm{MPa}]$ & $\varepsilon_{c p} \times 10^{-5}$ & $\sigma_{\text {res }}[\mathrm{MPa}]$ \\
\hline $0 \%$ & 0.64 & 1.89 & 32900 & 2.24 & 4.9 & 0 \\
\hline $0.4 \%$ & 0.55 & 1.87 & 33100 & 2.44 & 6.5 & 0.28 \\
\hline $0.6 \%$ & 0.53 & 1.75 & 30100 & 2.1 & 6.4 & 1.44 \\
\hline $0.8 \%$ & 0.44 & 1.64 & 29400 & 1.9 & 5.4 & 1.27 \\
\hline $1 \%$ & 0.42 & 1.45 & 29900 & 1.65 & 5.7 & 1.3 \\
\hline $1.2 \%$ & 0.46 & 1.79 & 26300 & 1.4 & 5.5 & 0.52 \\
\hline $1.5 \%$ & 0.1 & 0.32 & 25300 & 0.42 & 1.3 & 0.22 \\
\hline
\end{tabular}

\section{Characterization by Simple Compression Test}

Stress-strain curves in compression show a linear elastic domain and nonlinear domain (see Fig. 7). Part of the curve beyond the maximum stress corresponding to the maximum strength $f_{c j}$ is not recorded because the press used stops when the onset of macrocrack resulting from strain localization. 
The incorporation of chips in small quantities $(\mathrm{W}=0.4 \%)$ provides a slight increase in resistance $(18 \%)$ and rigidity. From $\mathrm{W}=0.6 \%$, fibers rather a decrease in resistance. For large concentrations of chips $(\mathrm{W}=1.2 \%)$ the decrease in resistance of fiber concrete $f_{c j}$ compared to the control concrete around $50 \%$ and the Young's modulus $\mathrm{E}_{\mathrm{b} 0}$ around $20 \%$ (see Table III and Fig. 8). This result is in agreement with those of Rossi [1], [4], Mamillan [3], Johnston [5] and Otter [6]. The most favorable content chips in the compressive behavior is $\mathrm{W}=0.4 \%$.

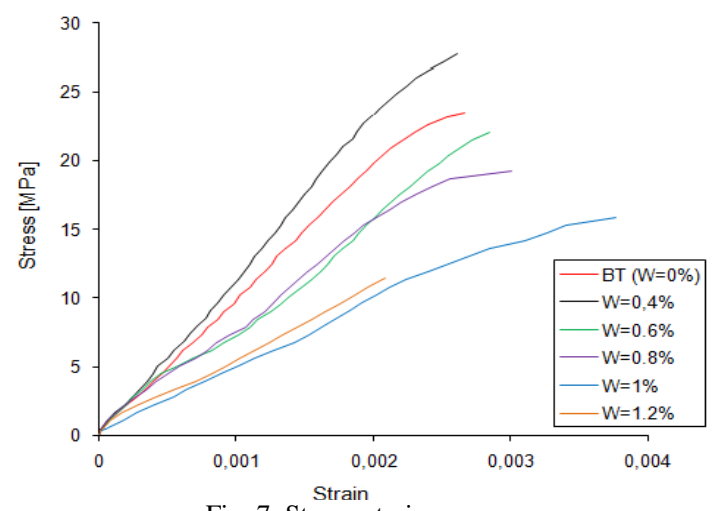

Fig. 7. Stress-strain curves.

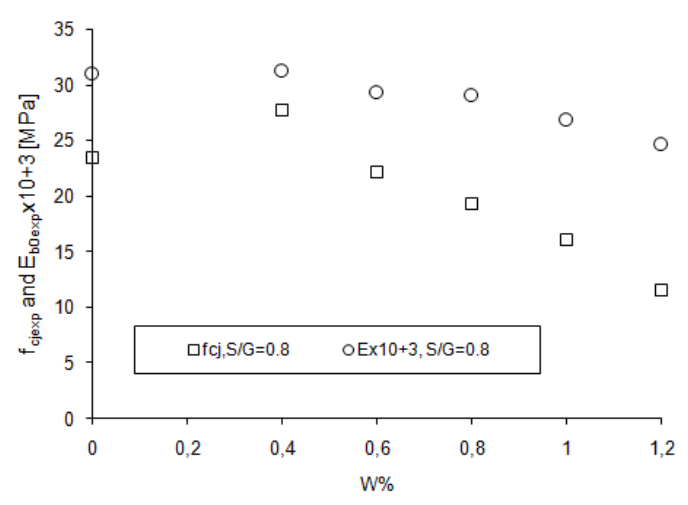

Fig. 8. fcj exp and Eb0 exp with $\mathrm{W}=0,6 \%$.

TABLE III: COMPARISON BETWEEN EXPERIMENTAL AND CALCULATED MECHANICAL CHARACTERISTICS VALUES.

\begin{tabular}{|c|c|c|c|c|c|c|c|}
\hline \multirow{2}{*}{$\begin{array}{c}\begin{array}{c}\text { Fiber } \\
\text { content }\end{array} \\
W \% \\
W \%\end{array}$} & \multirow[t]{2}{*}{$\begin{array}{l}\text { Compressive } \\
\text { strength } \\
f_{c i} \text { exp. (MPa) }\end{array}$} & \multicolumn{2}{|c|}{$\begin{array}{c}\text { Tensile } \\
\text { strength } \\
f_{f f}=\sigma_{c p}(\mathrm{MPa})\end{array}$} & \multicolumn{2}{|c|}{$\begin{array}{c}\text { Expéimental Young's } \\
\text { modulus } \\
(\mathrm{MPa}) \\
\end{array}$} & \multicolumn{2}{|c|}{$\begin{array}{c}\text { Calculated } \\
\text { Young's modulus } \\
(\mathrm{MPa}) \\
\end{array}$} \\
\hline & & $\begin{array}{l}f_{t i} \\
\text { exp. }\end{array}$ & $\begin{array}{c}f_{f i} \\
\text { calculese }\end{array}$ & $\begin{array}{c}\text { Compression } \\
E_{\text {b0exp }}\end{array}$ & $\begin{array}{c}\text { Traction } \\
E_{g y} \\
\end{array}$ & $\begin{array}{r}\text { Compression } \\
E_{\text {bocalculf }}\end{array}$ & $\begin{array}{c}\text { Iraction } \\
E_{t t}\end{array}$ \\
\hline $0 \%$ & 23.5 & 2.24 & 2.01 & 30934 & 32900 & 31507 & 30934 \\
\hline $0.4 \%$ & 27.73 & 2.44 & 2.26 & 31262 & 33100 & 33295 & 32021,67 \\
\hline $0.6 \%$ & 22.1 & 2.1 & 1.92 & 29305 & 30100 & 30869 & 30373,17 \\
\hline $0.8 \%$ & 19.25 & 1.9 & 1.75 & 29016 & 29400 & 29480 & 30426,18 \\
\hline $1 \%$ & 16.01 & 1.65 & 1.56 & 26832 & 29900 & 27719 & 28462,04 \\
\hline $1.2 \%$ & 11.5 & 1.4 & 1.29 & 24641 & 26300 & 24829 & 26437,33 \\
\hline
\end{tabular}

We note that the difference between calculated and measured values of strength and Young's modulus in tension is very low (see Fig. 9 and Fig. 10). The calculated values of the tensile strength are smaller than those measured 5 to $10 \%$. For the Young's modulus in tension and compression, the maximum deviation recorded is $6 \%$. This confirms the results obtained by the direct tensile test (see Table III).

$E_{b 0}$ calculated is the initial modulus of elasticity in comprecalculated with the formula given by BAEL [7]:

$$
E_{b o}=11000 \sqrt[3]{f_{c j}}
$$

$E_{c t}$ : elasticity modulus of the concrete in tension, calculated with the relation, as in [8]:

$$
E_{c t}=E_{b 0}(1+n \theta W)
$$

where: $E_{b 0}$ : initial modulus of concrete in compression, $n$ : equivalent coefficient steel - concrete $(n=15), \theta$ : fiber orientation factor for a three-dimensional orientation, $\theta=$ 0405, as in [8], [9] and $\mathrm{W}$ : volume percentage of fibers. $f_{t j}$ calculated $\left(\sigma_{c p}\right.$ calculated $)$ : tensile strength determined using the formula given by the BAEL : $f_{t j}=0.6+0.06 f_{c j}$

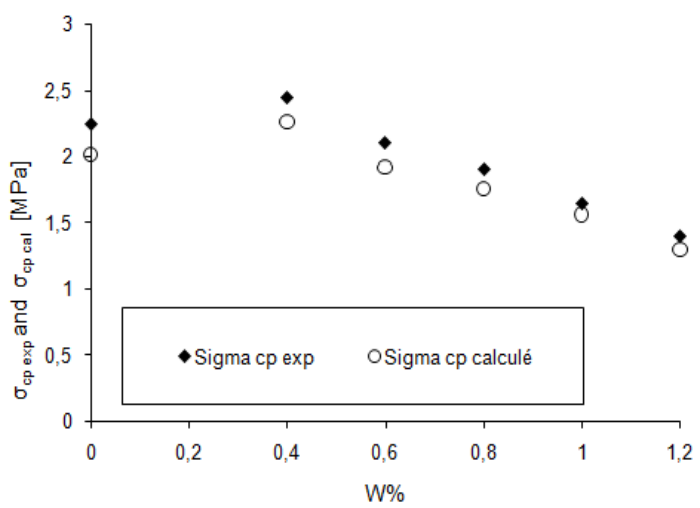

Fig. 9. Comparison between experimental and calculated values of tensile mechanical characteristics.

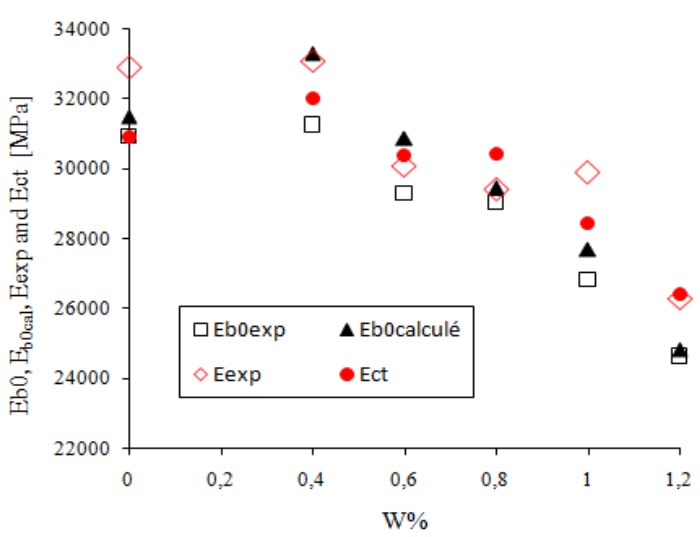

Fig. 10. Comparison between experimental and calculated values of compressive mechanical characteristics.

\section{Characterization by Three-Point Bending Test}

Curves forces - arrows of the fiber concrete (see Fig. 11) have a linear elastic domain and a domain nonlinear. They also have a bearing of ductility. While the control concrete breaks down rapidly after cracking, the fiber concrete continues as to resist forces even after the maximum load is reached. The incorporation of chips increases significantly the strength and deformation at break of the composite. We consider only $\mathrm{W}=0.6 \%$ and $0.8 \%$ that have the characteristics of traction most advantageous.

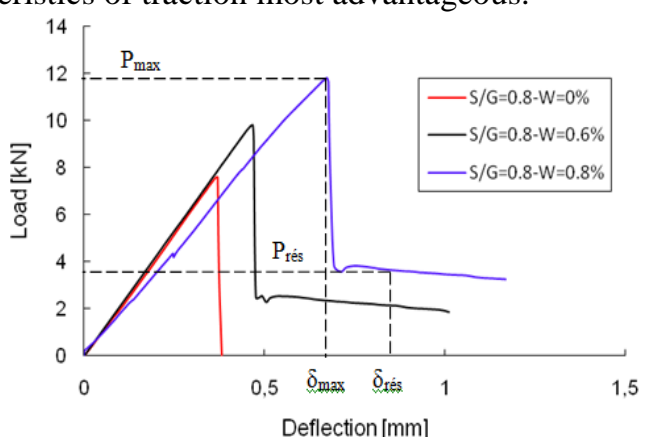

Fig. 11. Load-deflection curve. 


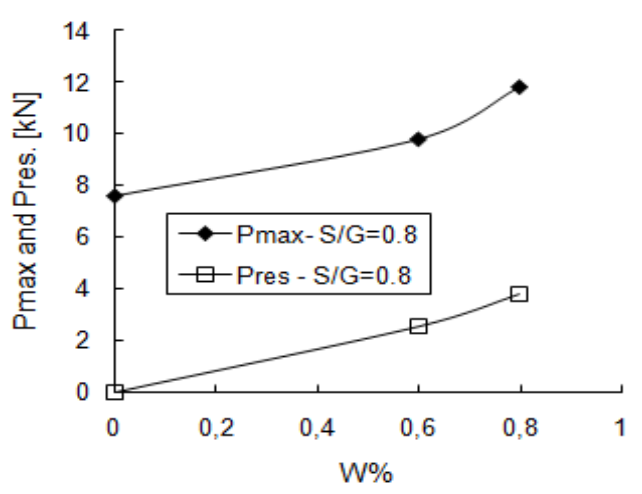

Fig. 12. Pmax and Pres versus W\%.

The effort to crack (Pmax) of fiber-reinforced concrete increases from 28 to $55 \%$ compared to the control concrete (see Fig. 12). It is the result of the presence of the chips in the stretched part of the section and allows the concrete to work more traction. Depending on the fiber, the residual capacity (Pres) represents $32 \%$ to $50 \%$ of the effort to control concrete cracking. As to the arrow, it increases more than $100 \%$ compared to the control concrete.

\section{E. Comparison of Performances of Chips with those of Conventional Fibers}

As a reference for comparison, we use the performance of corrugated fiber Eurosteel drawn steel with high mechanical strength [10] and Dramix marketed by Bekaert [11]. The criterion is the tensile strength under different stresses (see Table IV). The comparative study of the increase strength in concrete witness produced by the incorporation of fibers with the reference and the increase engendered by chips show that the contribution of this latter is not negligible. This increase represents $56 \%$ of that of conventional fibers for traction, and $100 \%$ for compression and bending.

TABLE IV: COMPARATIVE TABLE

\begin{tabular}{|l|c|c|c|}
\hline \multirow{3}{*}{$\begin{array}{c}\text { Mechanical } \\
\text { characteristics }\end{array}$} & \multicolumn{3}{|c|}{$\begin{array}{c}\text { Increase of the fiber reinforced concrete strength } \\
\text { relatively to that of concrete witness }\end{array}$} \\
\cline { 2 - 4 } & \multicolumn{3}{|c|}{ Renfort types. } \\
\cline { 2 - 4 } & Eurosteel fibers comgated & Dramix fibers & Steel chips \\
\hline Tensile strength & $16 \%$ & $*$ & $9 \%$ \\
\hline Compressive strength & $9 \%$ à $17 \%$ & $9,5 \%$ & $18 \%$ \\
\hline Bending strength & $55 \%$ & $54 \%$ & $55 \%$ \\
\hline
\end{tabular}

\section{CONCLUSION}

Characterization by direct tensile test the mechanical behavior of fiber reinforced concrete showed that the presence of chips improves the resistance to cracking of the composite and introduced some ductility in the post - rupture behavior. The mechanical behavior is described by a linear elastic phase and a non-linear phase before the break. This is followed by a sudden drop in the effort to stabilize at a level corresponding to the residual capacity developed in the final stage. An identical behavior is found by bending tests.

Compression tests show that adding a small percentage of chips provides a slight increase in strength and stiffness, by cons, with the increased volume of reinforcements, rather these characteristics tend to decrease.

Tensile tests show a clear bending behavior improvement following the incorporation of chips. This improvement appears clearly in the post-cracking having an important ductility bearing.

In summary we can say that small percentage, chips increase the strength of fiber reinforced concrete by delaying the location of the crack, bridging microcracks and introduce some ductility in the post - rupture behavior by taking efforts through the macrocrack. A high content, reducing the compactness of the concrete causes a reduction of its tensile strength and compressive strength. Concrete composition which has the highest tensile strength and compressive stress and the largest of crack initiation is the one containing $0.4 \%$ fiber. For cons, the composition of fibers is $0.6 \%$ which guarantees a better compromise strength - ductility.

The comparison of the mechanical properties of concrete chips with those of two reference concrete (concrete reinforced with conventional fibers: undulated Eurosteel and Dramix) shows that the chips confer to the concrete a significant increase in resistance. With a significant increase in strength and a notable contribution of ductility in the post-failure behavior of the composite, recycling chips as reinforcement for concrete may be considered.

For the studied stresses, concrete reinforced with chips has mechanical characteristics equivalent to those of reinforced concrete with conventional fibers.

\section{REFERENCES}

[1] P. Rossi, "The industrial development of metal fiber concretes-conclusions and recommendations," Press of the National School of Bridges and Roads, France, 2002.

[2] P. Casanova, P. Rossi, and I. Schaller, "The steel fibers can they replace transverse reinforcement in reinforced concrete beams," Central Laboratory of Bridges and Roads, LCPC, France, Newsletter no. 195, January 1995.

[3] M. Mamillan and J. Minard, "Concrete steel fibers", Experimental Central Building Research and Public Works, CEBTP, France, Research, no. 91-1015, October 1987.

[4] P. Rossi, "Formulation and mechanical behavior of armed metallic fiber concrete," Annals of the Technical Institute of Building and Public Works, France, no. 492, Concrete Series no. 79, pp. 90-101, March-April 1991.

[5] C. D. Jonston, "Properties steel fiber reinforced mortar and concrete," in Proc. Symposium on Fibrous, London, 1980.

[6] D. Otter and A. E. Naaman, "Steel fiber reinforced concrete under static and cyclic compressive loading," in Proc. 3rd International Symposium, Sheffield, 1986.

[7] BAEL, Rules of reinforced concrete for Limit States, $2^{\text {nd }}$ ed. France: Eyrolles, 1993, ch. A2, pp. 7-13.

[8] Y. Bouafia, B. Fouré, and M. S. Kachi, "Load-crack opening relationship in the case of reinforced concrete with steel fibers," Annals of the Technical Institute of Building and Public Works, France, no. 2, pp. 5-14, April 1998

[9] Y. Bouafia, M. S. Kachi, and B. Fouré, "Stress-strain relationship in tension of concrete steel fiber," Annals of the Technical Institute of Building and Public Works, France, no. 3, pp. 5-17, June 2002.

[10] Z. Zhan, "Contribution to the design of concrete piles fiber," Ph.D thesis, Orléans Univ., France, 1991.

[11] A. Adjrad, "Reinforcement of concrete with metal shavings Experimental study and modeling," Magister thesis, Tizi-Ouzou Univ., Algeria, 2000.

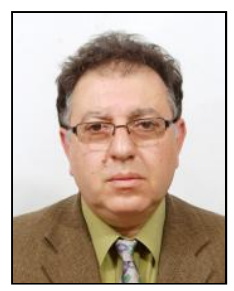

Youcef Bouafia was born in August 29, 1961 in Algeria. Since 2003 he is a professor at University "Mouloud Mammeri" of Tizi-Ouzou, 15000, Algeria and Lecturer from 1993 to 2003. And he became doctor of Ph.D. Thesis of Central School, Paris in 1991.

$\mathrm{He}$ is a member of Laboratory LaMoMS (Experimental and Numerical Modeling of Materials and Structures of Civil Engineering), UMMTO and 
was a director of laboratory "LaMoMS" from 2002 to 2012 and the head of department of Civil Engineering from 1999 to 2002.

Prof. Bouafia is invested in research themes: materials and composites, experimentation, external prestressing, numerical modeling and nonlinear calculation of structures.

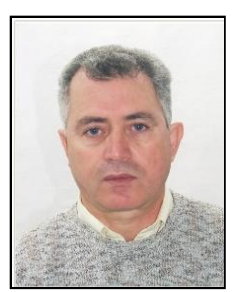

Said Djebali was born in 1956 in Algeria. He is a member of Laboratory LMSE (Mechanical, energy and structures) and works as an assistant lecturer since 1988 at University "Mouloud Mammeri" of Tizi-Ouzou, 15000 in Algeria.

Mr. Djebali is invested in research themes: materials and composites, experimentation, mechanical behavior.

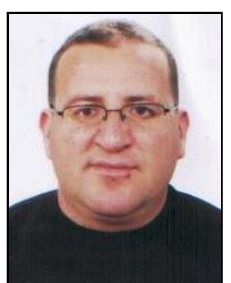

Djamal Atlaoui was born in December 22, 1973 in Algeria. He is a member of Laboratory LaMoMS (Experimental and Numerical Modeling of Materials and Structures of Civil Engineering) and works as an assistant lecturer since 2004 at University "Mouloud Mammeri" of Tizi-Ouzou, 15000 in Algeria

Mr. Atlaoui is invested in research themes: materials, experimentation, mechanical behavior.

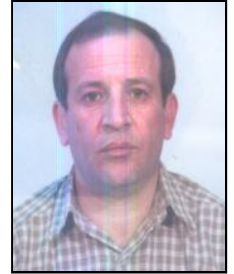

Mohand Said Kachi was born in May 3, 1966 in Algeria. He became a doctor in University of Tizi-Ouzou in 2006.

He was a member of the laboratory LaMoMS Experimental and Numerical Modeling of Materials and Structures of Civil Engineering) since 2002 and work as a professor at University "Mouloud Mammeri" of Tizi-Ouzou, 15000, Algeria and Lecturer from 1993 to 2012.

Prof. Kachi is invested in research themes: materials, experimentation, external prestressing, numerical modeling and nonlinear calculation of structures. 